\title{
Bemerkung zum Aufsatze: „Die ebenen Vielecke und die Winkel mit Einschluss der Berührungswinkel als Systeme von absoluten Grössen “. ${ }^{1}$ )
}

Von 0. Stolz in Innsbruck.

1. Wie mich eine Zuschrift des Hrn. F. Schur vom 24. Nov. 1894 belehrte, so habe ich das Referat über seinen Vortrag nicht richtig verstanden. Thatsächlich handelt es sich um Beseitigung des Axioms: "Das Ganze ist größer als sein Theil", welches als solches neben den auch von mir benutzten Definitionen der gleichen Vielecke und des größßeren Vielecks nicht stehen bleiben darf. Wie dies bewerkstelligt werden kann, hat Schur a. a. $O$. angegeben. Man braucht nur zuerst jedem Vielecke ein Rechteck von gegebener Grundlinie so zuzuordnen, dass, wenn man das Vieleck irgenndwie durch gerade Strecken in Stücke zerschneidet, dieses Rechteck sich durch Parallele zur Grundlinie so in gleich viele Theile zerlegen lässt, dass je ein Stïck des Vielecks und je ein Theil des Rechteckes in gleichviele paarweise congruente Stücke getheilt werden können. Hierbei handelt es sich u. A. um den Beweis des Satzes, dass die den Dreiecken $B C O, C A O, A B O$ (worin $O$ einen beliebigen Punkt der Ebene $A B C$ bedeutet) entsprechenden Rechtecke mit der Basis $g$ zusammengefügt das dem Dreiecke $A B C$ entsprechende Rechteck mit der Basis $g$ liefern. ${ }^{2}$ )

2. Ferner berichtige ich, dass das a. a. O. Nr. 2 betrachtete System, welches aus den hohlen Winkeln und gewissen Berührungswinkeln besteht, nicht als ein System von uneigentlichen absoluten Größen in dem auf S. 70 meiner Vorles. iiber allg. Arithmetik I. Bd. angegebenen Sinne bezeichnet werden kann, weil die Addition dieser Größen nicht völlig der der natürlichen Zahlen analog ist. Sie weicht von dieser nämlich in einigen Ungleichungen $a b$, so schon darin, dass manchmal die Summe zweier Gröben gleich ist einem der Addenden.

1) Diese Monatshefte V. Jahrgang, S. 233.

$\left.{ }^{2}\right)$ Auch Hr. Rausenberger hat in einem Artikel in den Math. Ann., 43. Bd., S. 601 das nämliche Ziel erreicht, wenn auch bei etwas anderer, mehr abstracter Formulierung des Grundgedankens. 